\title{
Erratum to: Sex-specific macronutrient foraging strategies in a highly successful marine predator: the Australasian gannet
}

\author{
Gabriel E. Machovsky-Capuska ${ }^{1,2,3} \cdot$ Alistair M. Senior ${ }^{2,4} \cdot$ Emily C. Benn $^{3}$ • \\ Alice H. Tait ${ }^{5}$ Rob Schuckard ${ }^{6} \cdot$ Karen A. Stockin $^{5} \cdot$ Willie Cook $^{6} \cdot$ Mike Ogle $^{7}$. \\ Katherine Barna $^{2} \cdot$ David Melville $^{6} \cdot$ Belinda Wright $^{1} \cdot$ Cameron Purvin $^{5}$. \\ David Raubenheimer ${ }^{1,2,3}$
}

Published online: 30 March 2016

(C) Springer-Verlag Berlin Heidelberg 2016

\section{Erratum to: Mar Biol (2016) 163:75 \\ DOI 10.1007/s00227-016-2841-y}

Unfortunately, the second research question was incorrectly published in the "Introduction" and "Results" sections of the original article. The correct question is given below.

Do female and male Australasian gannets target different prey combinations?

The online version of the original article can be found under doi:10.1007/s00227-016-2841-y.

Gabriel E. Machovsky-Capuska

g.machovsky@sydney.edu.au

1 School of Life and Environmental Sciences, Faculty of Veterinary Sciences, The University of Sydney, Sydney, Australia

2 Charles Perkins Centre, The University of Sydney, Sydney, Australia

3 School of Life and Environmental Sciences, The University of Sydney, Sydney, Australia

4 School of Mathematics and Statistics, The University of Sydney, Sydney, Australia

5 Institute of Natural and Mathematical Sciences, Massey University, Auckland, New Zealand

6 Ornithological Society of New Zealand, Wellington, New Zealand

7 Department of Conservation, Golden Bay Area, Takaka, New Zealand 